\title{
The effect of iron fortification and de-worming on anaemia and iron status of Vietnamese schoolchildren
}

\author{
Huong Thi Le ${ }^{1}$, Inge D. Brouwer ${ }^{2}$, Khan Cong Nguyen ${ }^{3}$, Jan Burema ${ }^{2}$ and Frans J. Kok ${ }^{2}$ \\ ${ }^{1}$ The Nutrition Department, Hanoi Medical University, No. 1 Ton That Tung Str., Dongda, Hanoi, Viet Nam \\ ${ }^{2}$ The Division of Human Nutrition, Wageningen University, P.O. Box 8129, 6700 EV Wageningen, The Netherlands \\ ${ }^{3}$ The National Institute of Nutrition, No. 48B Tang Bat Ho Str., Hanoi, Viet Nam
}

(Received 28 June 2006 - Revised 15 November 2006 - Accepted 20 November 2006)

\begin{abstract}
Previous data from Vietnam show that anaemia is highly prevalent among schoolchildren, who are considered not to be iron deficient. Trichuris infection doubled the risk of anaemia. The present study aimed to evaluate the hypothesis that de-worming is more effective than iron fortification in an anaemic, infection-prone population. In a trial with a $2 \times 2$ factorial design, 425 anaemic children aged $6-8$ years were randomly assigned to receive either iron-fortified noodles or placebo, and mebendazole or placebo. Outcomes considered were change in haematological indicators of iron status $(\mathrm{Hb}$, serum ferritin $(\mathrm{SF})$, serum transferrin receptor (TfR) and haemoglobinopathies analysis); inflammations (C-reactive protein (CRP)); parasite infection status (hookworm, Trichuris and Ascaris infection); and IgE. ANOVA and logistic regression were used to assess the effects of iron fortification and de-worming on $\mathrm{Hb}, \mathrm{SF}$, TfR, body iron and anaemia. Hb improved in all groups after 6 months of intervention. Iron fortification significantly improved $\mathrm{Hb}, \mathrm{SF}$ and body iron $(2.6 \mathrm{~g} / \mathrm{l}, 16.3 \mu \mathrm{g} / \mathrm{l}$ and $1 \mathrm{mg} / \mathrm{kg}$, respectively). Prevalence of elevated IgE was very high at baseline (99\%) and significantly reduced to about $75 \%$ in all groups after intervention. De-worming unexpectedly showed no effect on Hb, iron status and $\mathrm{IgE}$ level. It is concluded that iron fortification slightly improved anaemia and iron status in anaemic schoolchildren in rural Vietnam that were not considered iron deficient. Chronic infection or other unidentified factors may play an important role in the seasonal reduction of anaemia seen in all treatment groups.
\end{abstract}

Anaemia: Iron deficiency: Iron fortification: De-worming: Children: Vietnam

Anaemia is a significant public health problem in Vietnam. The 2000 National Nutrition Risk Factor Survey in Vietnam showed an anaemia prevalence of $34 \%$ in children under 5 and $25 \%$ in women (Ninh et al. 2001). No nationally representative data are available on the prevalence of anaemia among primary schoolchildren in Vietnam; however, a few local studies showed an anaemia prevalence of around $30 \%$ (Le, 1999; Hoa, 2002). Although various nutrients and cofactors are involved in maintaining the normal synthesis of $\mathrm{Hb}$, iron deficiency is the most frequent cause of anaemia on a worldwide basis (Osório, 2002). However, infection and inflammation (Yip \& Dallman, 1988; Means, 2000), malaria (Fleming, 1981), intestinal parasite infection (Stoltzfus et al. 1997, 2000), as well as haemoglobinopathies (Dugdale, 2001; INACG, 2002) may play a role. Their relative importance in Vietnam is still unclear. A previous cross-sectional study conducted in Tam Nong district, Phu Tho province, a poor rural area of North Vietnam, showed a high prevalence of anaemia among primary schoolchildren with low iron deficiency as measured by serum transferrin receptor (TfR) and serum ferritin (SF) with $2 \%$ of children with TfR $>8.5 \mathrm{mg} / \mathrm{l}$ and $0.5 \%$ of children with $\mathrm{SF}<12 \mu \mathrm{g} / \mathrm{l}$ (Le et al. 2005). Further, Trichuris infection was associated with a doubled risk of anaemia, probably not mediated through iron deficiency. Food fortification is often suggested as one of the most effective and sustainable strategies for increasing iron intake in the general population (Hurrell, 1997). Also in the nutritional strategies for prevention and control of micronutrient deficiencies in Vietnam, food fortification is considered as a sustainable solution to combat iron deficiency anaemia (Ninh et al. 2001). However, based on the previous study, it is hypothesized that de-worming is more effective than iron fortification in an anaemic, infection-prone population that was not considered iron deficient. Using a trial with iron-fortified noodles and de-worming, we assessed the changes in iron and anaemia status among anaemic schoolchildren, and tested whether the present data are consistent with this hypothesis.

\section{Subjects and methods \\ Study design and population}

The study was implemented from November 2004 to May 2005 in six primary schools in Tam Nong district, Phu Tho province, situated $90 \mathrm{~km}$ from Hanoi. Selection was based

\footnotetext{
Abbreviations: CRP, C-reactive protein; MEB, mebendazole; SF, serum ferritin; TfR, serum transferrin receptor.

*Corresponding author: Mrs Huong Thi Le, No. 41 Lane 101, Pham Ngoc Thach Str., Dongda, Hanoi, Vietnam, fax +84 4 7337955, email huong.lethi@wur.nl or email donghuong@fpt.vn
} 
on high prevalence of anaemia and absence of interventions to control iron-deficiency anaemia in schoolchildren. Children recruited into the study were in Grades $1-3$ with $\mathrm{Hb}$ concentrations $<110 \mathrm{~g} / \mathrm{l}$ but not $<70 \mathrm{~g} / \mathrm{l}$ in an initial $\mathrm{Hb}$ screening study. We excluded children with $\mathrm{Hb}$ level less than $70 \mathrm{~g} / \mathrm{l}$ because these children were considered to be severely anaemic and received treatment immediately. The study concerns a randomized, placebo-controlled double-blind parallel trial with a $2 \times 2$ factorial design plus standard treatment (iron supplementation and de-worming) and an intervention period of 6 months. A total of 425 eligible children were randomly assigned to one of five groups receiving: (1) iron-fortified noodles and mebendazole (Fe + MEB); (2) noodles without iron fortificant and mebendazole (MEB); (3) iron-fortified noodles and placebo (Fe); (4) noodles without iron fortificant and placebo (placebo); and (5) iron supplementation and mebendazole (Fe tablet $+\mathrm{MEB}$ ) (Fig. 1). Randomization was carried out by a researcher from the Division of Human Nutrition, Wageningen University, The Netherlands, who did not know the children and could not introduce bias in the randomization. Stratified randomization was applied based on the $\mathrm{Hb}$ levels and age of the children to ensure equal distribution of $\mathrm{Hb}$ and age across groups. Sample size was assessed to achieve a statistical power of $95 \%$, based on an $\alpha$ error of 0.05 , a between-group difference in treatment effect of $5 \mathrm{~g} \mathrm{Hb} / \mathrm{l}$ in $\mathrm{Hb}$ concentration being clinically relevant, a standard deviation of $11 \mathrm{~g} / \mathrm{l}$ (Hoa, 2002) and accounting for $10 \%$ of children being lost in the course of the intervention. In this paper we focus on the placebo-controlled parallel trial with a $2 \times 2$ factorial design to assess the effect of iron-fortified noodle and de-worming on iron and anaemia status of schoolchildren. The extent of the effect of the ironfortified noodles compared to the standard treatment and its policy relevance is discussed in another paper (Le, 2006).
Children were invited for the study and a written informed consent was obtained from their parents. The study was approved by the Scientific Committee of the National Institute of Nutrition and the Ethics Committee of Hanoi Medical University - Ministry of Health.

\section{Products and field procedures}

Fortified instant noodles were produced at the Hanoi Food Company. Noodles were fortified with a water-soluble, highly bioavailable iron compound (NaFeEDTA: Ferrazone ${ }^{\circledR}$; Akzo Nobel Chemicals Pte Ltd, Arnhem, The Netherlands) to a fortified level of $10.7 \mathrm{mg}$ iron $/ 52 \mathrm{~g}$ noodles calculated based on the JECFA recommendation of an acceptable daily intake of $2.5 \mathrm{mg}$ EDTA $/ \mathrm{kg}$ body weight (JECFA, 1974) and an average body weight of $29 \mathrm{~kg}$ (Food \& Agriculture Organization \& World Health Organization, 1998). Before intervention retention of iron after production and preparation of fortified instant noodles was checked in laboratories at the National Institute of Nutrition Hanoi, Wageningen University and Akzo Nobel Chemicals Pte Ltd. Capillary zone electrophoresis analysis (Sheppard \& Henion, 1997) showed that $70 \%$ of the NaFeEDTA dissolves within 5 min into the soup independent of extraction time. No degradation products of NaFeEDTA were found.

Noodles were prepared in school by caretakers trained by field staff. The whole content of a package of instant noodles $(52 \mathrm{~g})$ was broken into smaller pieces and put into a plastic heat-resistant bowl together with seasoning. Hot boiled water from a thermos flask $(200 \mathrm{ml})$ was added to the noodles and given to children at break time ( 09.00 hours) $5 \mathrm{~d} /$ week for 6 months under the supervision of teachers and field staff. Children were encouraged to consume all the noodles and water. During the intervention, $100 \%$ of the study population consumed the given noodles or iron tablet. More than $95 \%$ of

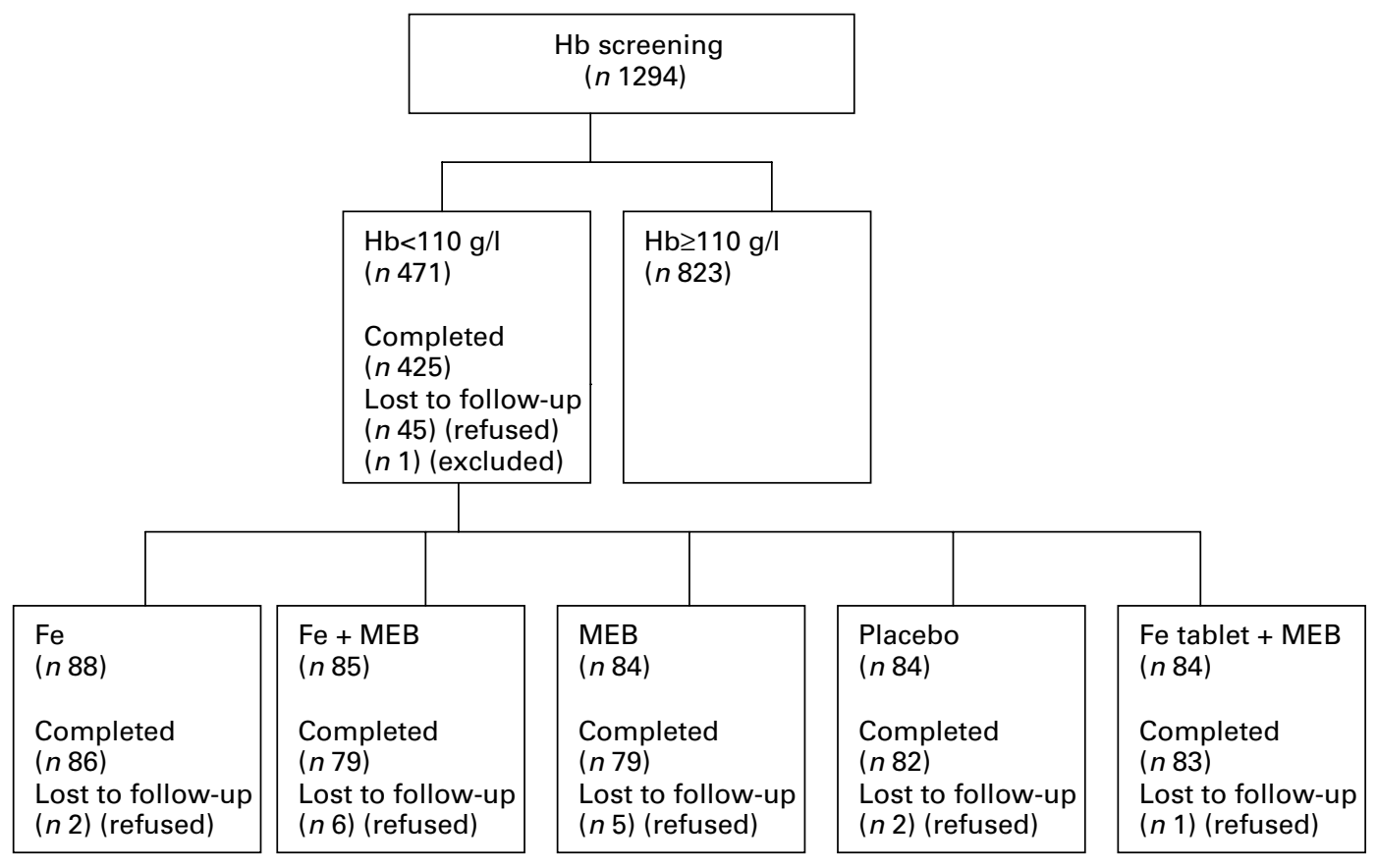

Fig. 1. Study profile: initial screening to enrol anaemic children in the study, followed by a 6-month intervention of: Fe, iron-fortified noodles and placebo; $\mathrm{Fe}+\mathrm{MEB}$, iron-fortified noodles and mebendazole; MEB, noodles without iron fortificant and mebendazole; Placebo, noodles without iron fortificant and placebo; Fe tablet + MEB, iron supplementation and mebendazole. 
children were present every school day ( $5 \mathrm{~d} /$ week) and more than $95 \%$ finished the whole portion of the noodles given to them daily under the supervision of caretakers and field staff (based on notes taken by caretakers in a monitoring book).

MEB (500 mg) and an identical placebo were given to children at the beginning of the intervention and after 3 months. Children, teachers and researchers were blinded to the treatment.

\section{Data collection}

Capillary blood samples were taken from children's fingers during screening for $\mathrm{Hb}$ measurement by a cyanmethaemoglobin method. Children's weight was measured to the nearest $100 \mathrm{~g}$ using an electronic scale (Seca 890; Seca, Birmingham, UK) and standing height was measured to the nearest $1 \mathrm{~mm}$ with a microtoise (Stanley Mabo no. 191; Stanley Mabo, Poissy, France) during baseline and after intervention. Venous blood $(5 \mathrm{ml})$ was collected in the morning at baseline (T0) and after intervention (T6); $20 \mu \mathrm{l}$ whole blood was pipetted immediately before coagulating into a tube containing $5.0 \mathrm{ml}$ Drabkin's reagent with a Sali pipette for $\mathrm{Hb}$ measurement. An aliquot of whole blood was taken for analysing haemoglobinopathies. The remaining blood was allowed to clot for $30 \mathrm{~min}$ at room temperature, centrifuged at $3000 \mathrm{~g}$ for $15 \mathrm{~min}$ and transferred to five plastic labelled vials $(0.5 \mathrm{ml}$ Eppendorf tubes). The vials were stored in a box protected from sunlight and put into an ice box for transfer to the laboratories and kept at $-80^{\circ} \mathrm{C}$ until $\mathrm{SF}, \mathrm{TfR}, \mathrm{C}$-reactive protein (CRP) and IgE analysis at the end of the intervention.

For assessment of intestinal parasite infection before and after intervention, containers for collection of stools were distributed to each class and children were asked to collect and deliver a sample of their faeces to school the next day. In cases where children were unable to return a sample, one of the field workers returned the next day to collect the rest of the samples.

\section{Laboratory analysis}

$\mathrm{Hb}$ concentration was measured in whole blood within $12 \mathrm{~h}$ of sampling by a cyanmethaemoglobin method using a Sigma Kit (Sigma Chemical Co., St Louis, MO, USA) in the Tamnong District Health Centre. The CV of intra-assays and interassays was $4.0 \pm 1.2$ and $5.0 \pm 2.0 \%$, respectively. SF, TfR, $\mathrm{CRP}$ and $\mathrm{IgE}$ analysis was carried out at the same time for both samples of baseline and after intervention at the National Institute of Nutrition and the laboratory of Hanoi Medical University in May and June 2005. Concentrations of SF and TfR were analysed by an ELISA method (catalogue numbers S-22 and TF-94; Ramco Laboratories Inc., Houston, TX, USA), with inter-assay variability of $4-7 \%$ and $4-8 \%$, respectively. Serum CRP was measured by nephelometry using Epress plus, with an inter-assay variability of $4-8 \%$. Serum IgE was determined by ELISA using the Kallestad Total IgE Microplate Kit from Kallestad GmbH (Mannheim, Germany), with an inter-assay variability of $4-6 \%$. A $10 \%$ subsample was re-examined for quality control. Haemoglobinopathies analysis was performed by using the Variant BetaThalassemia Short Program (Bio-Rad Laboratories Inc., Hercules, CA, USA) within $24 \mathrm{~h}$ of sampling in the Children's Hospital, Hanoi, Vietnam. Stools samples were examined using the Kato-Katz Technique - a cellophane faecal thick smear method (World Health Organization, 1991). Hookworm, Trichuris and Ascaris eggs were counted. A $10 \%$ subsample of smears was re-examined for quality control.

\section{Data analysis}

Anthropometric indices were calculated using WHO/NCHS reference data (World Health Organization, 1995). Being wasted, stunted and underweight was defined by $z$-scores $<-2$ sD for weight-for-height, height-for-age and weight-forage, respectively. Anaemia was defined as $\mathrm{Hb}$ concentrations $<115 \mathrm{~g} / \mathrm{l}$ (World Health Organization, 2000). Iron deficiency was defined as SF concentrations $<12 \mu \mathrm{g} / \mathrm{l}$ (World Health Organization, 2000), and tissue iron deficiency was defined as TfR concentration $>8.5 \mathrm{mg} / \mathrm{l}$ (Skikne et al. 1990). Body iron content was calculated using the following formula: body iron $(\mathrm{mg} / \mathrm{kg})=-(\log (\mathrm{TfR} / \mathrm{SF}$ ratio $)-2 \cdot 8229) / 0 \cdot 1207$ (Cook et al. 2003).

CRP and IgE concentrations were considered to be elevated when $\geq 8 \mathrm{mg} / 1$ (Hoffbrand \& Pettit, 1993) and $>90 \mathrm{IU} / \mathrm{ml}$ (Heil et al. 2000), respectively. Hb type was determined in each subject on the basis of haematological indexes: HbAA (normal haemoglobin type), $\mathrm{HbF}$ (haemoglobin $\mathrm{F}$ ); $\mathrm{HbA} 2$ (haemoglobin A2); HbAE (trait for haemoglobin $\mathrm{E}$ disease) or $\mathrm{HbEE}$ (haemoglobin $\mathrm{E}$ disease). Severity of intestinal worm infections was expressed as the number of eggs/g faeces using the WHO classification system (World Health Organization, 1987).

Data were entered into the computer, cleaned and managed using Epi Info version 6 (Dean et al. 1995) and analysed using SPSS version 11.0 for Windows (SPSS Inc., Chicago, IL, USA; Field, 2005). Data were checked for normality by visual inspection. One-way ANOVA was used to determine differences in $\mathrm{Hb}$ concentration and other biochemical indicators between groups. Paired $t$ test was used to compare $\mathrm{Hb}$ and other biomarkers before and after intervention. $\chi^{2}$ test and McNemar test were used to assess the differences in proportions between and within groups. To assess the effect of iron fortification and de-worming on indicators of iron status, we calculated dummy variables for each treatment (iron fortification and de-worming), as well as their interaction. The effect on change in $\mathrm{Hb}$ concentration, SF, TfR and body iron, respectively, was then assessed by including them in a general linear model, so as to simulate a two-way ANOVA. In all regression analyses, we adjusted for concentration at baseline, sex and age, and sometimes CRP or thalassaemia. Logistic regression was used similarly to study the effect of iron fortification and de-worming on anaemia prevalence, adjusting for baseline characteristics.

\section{Results}

At baseline, the mean age of children was 87.4 (SD 10.2) months. The four groups did not significantly differ in age, $\mathrm{Hb}$ concentration, iron status ( $\mathrm{SF}, \mathrm{TfR}$ and body iron) and nutritional status (Table 1) nor in CRP, IgE status and parasite infection (Table 2). The prevalence of iron deficiency was very low as only $1.2 \%$ of children showed SF concentration below $12 \mu \mathrm{g} / \mathrm{l}$ and $5.5 \%$ of children showed TfR above $8.5 \mathrm{mg} / \mathrm{l}$. Mean body iron was around $6.3 \mathrm{mg} / \mathrm{kg}$ body weight (Table 1). Two-thirds of the children were infected with 
Table 1. Baseline characteristics by treatment group in rural Vietnamese schoolchildren $(n 409) \S$

\begin{tabular}{|c|c|c|c|c|c|c|c|c|c|c|}
\hline & \multicolumn{10}{|c|}{ Treatment groups\| } \\
\hline & \multicolumn{2}{|c|}{$\mathrm{Fe}(n 86)$} & \multicolumn{2}{|c|}{$\mathrm{Fe}+\mathrm{MEB}(n 79)$} & \multicolumn{2}{|c|}{ MEB $(n 79)$} & \multicolumn{2}{|c|}{ Placebo ( $n$ 82) } & \multicolumn{2}{|c|}{$\begin{array}{c}\text { Fe tablet }+ \text { MEB } \\
(n 83)\end{array}$} \\
\hline & Mean & SD & Mean & SD & Mean & SD & Mean & SD & Mean & SD \\
\hline Male sex (\%) & $51 \cdot 2$ & & $50 \cdot 6$ & & $46 \cdot 8$ & & $48 \cdot 8$ & & $53 \cdot 0$ & \\
\hline Age (months) & 88.0 & $10 \cdot 1$ & $87 \cdot 6$ & 11.4 & $87 \cdot 7$ & $10 \cdot 1$ & 86.9 & $10 \cdot 3$ & 86.9 & $9 \cdot 8$ \\
\hline $\mathrm{Hb}(\mathrm{g} / \mathrm{l})$ & 107.5 & $8 \cdot 3$ & $107 \cdot 3$ & $6 \cdot 8$ & 108.5 & 6.9 & $107 \cdot 8$ & $6 \cdot 2$ & 107.9 & $7 \cdot 2$ \\
\hline Serum ferritin $(\mu \mathrm{g} / \mathrm{l})$ q & $55 \cdot 0$ & $33 \cdot 0,78 \cdot 8$ & 47.4 & $33 \cdot 7,67 \cdot 5$ & 58.9 & $40 \cdot 0,85 \cdot 5$ & 53.2 & $35 \cdot 4,77 \cdot 6$ & $58 \cdot 2$ & $40 \cdot 5,72 \cdot 5$ \\
\hline Transferrin receptor (mg/l) & 5.9 & $3 \cdot 0$ & $6 \cdot 0$ & 1.4 & $6 \cdot 2$ & 1.5 & $6 \cdot 2$ & 1.6 & $6 \cdot 0$ & $1 \cdot 3$ \\
\hline Body iron $(\mathrm{mg} / \mathrm{kg})$ & $6 \cdot 5$ & $2 \cdot 3$ & $6 \cdot 1$ & $2 \cdot 3$ & 6.5 & $2 \cdot 7$ & $6 \cdot 2$ & $2 \cdot 7$ & $6 \cdot 6$ & 1.9 \\
\hline Serum ferritin < $12 \mu \mathrm{g} / \mathrm{l}(\%)$ & $1 \cdot 2$ & & $1 \cdot 3$ & & 1.3 & & $1 \cdot 2$ & & 0.0 & \\
\hline Transferrin receptor $>8.5 \mathrm{mg} / \mathrm{l}(\%)$ & 3.5 & & $3 \cdot 8$ & & $6 \cdot 3$ & & 8.5 & & 3.6 & \\
\hline WAZ & $-1 \cdot 8$ & 0.8 & -1.9 & 0.6 & -1.9 & 0.6 & -1.9 & 0.6 & -1.7 & 0.6 \\
\hline HAZ & -1.6 & 0.7 & -1.6 & $0 \cdot 8$ & $-1 \cdot 7$ & 0.8 & $-1 \cdot 7$ & 0.8 & -1.6 & $0 \cdot 8$ \\
\hline WHZ & $-1 \cdot 2$ & 0.8 & $-1 \cdot 2$ & 0.7 & $-1 \cdot 2$ & 0.7 & $-1 \cdot 2$ & 0.6 & $-1 \cdot 0$ & 0.7 \\
\hline Thalassaemia (\%) & $9 \cdot 3$ & & $6 \cdot 3$ & & 3.8 & & 8.5 & & 8.4 & \\
\hline
\end{tabular}

WAZ, weight-for-age $z$-score; HAZ, height-for-age $z$-score; WHZ, weight-for-height $z$-score.

$\S$ Values are means and standard deviations unless otherwise indicated.

II Fe, iron-fortified noodles and placebo; Fe + MEB, iron-fortified noodles and mebendazole; MEB, noodles without iron fortificant and mebendazole; Placebo, noodles without iron fortificant and placebo; Fe tablet + MEB, iron supplementation and mebendazole.

II Values are medians with 25th and 75th percentiles.

Ascaris and/or Trichuris, and about $8.6 \%$ were infected with hookworm. However, the intensity of Ascaris and Trichuris infection was mainly 'light' or 'average', and only $27 \%$ and $2 \%$ among infected children showed severe infection with Ascaris or Trichuris, respectively. The hookworm infection was 'light' for most of the cases (data not show). Very few children showed elevated CRP levels $(1.8 \%)$ and $99 \%$ of the children showed an elevated IgE level (Table 2). The prevalence of thalassaemia ( $\mathrm{HbA} 2, \mathrm{HbAE}, \mathrm{HbF})$ was around $7 \%$ (Table 1).

$\mathrm{Hb}$ concentration increased after 6 months of intervention in all four groups; however, a larger significant increase was seen in the two groups receiving iron-fortified noodles (17.8 and $17.5 \mathrm{~g} / \mathrm{l}$, respectively) compared to $14.6 \mathrm{~g} / \mathrm{l}$ in the group receiving de-worming only and $15.4 \mathrm{~g} / \mathrm{l}$ in the placebo group (Table 3). Prevalence of anaemia significantly decreased in all four groups with a larger reduction observed in the two iron-fortified groups; however, no significant differences were found between groups (Table 3).

SF concentration increased significantly in the two groups receiving iron fortification ( 15.0 and $17.9 \mu \mathrm{g} / \mathrm{l}$, respectively). This was not the case in the other two groups: the group receiving only de-worming even showed a decrease in SF concentration compared with data at baseline $(-7.9 \mu \mathrm{g} / \mathrm{l}$; Table 3$)$.

TfR concentration was slightly improved after 6 months of intervention in all groups (Table 3).

Body iron significantly increased in the two groups receiving iron fortification $(1.0$ and $1.4 \mathrm{mg} / \mathrm{kg})$ with smaller changes in the de-worming only $(-0.1 \mathrm{mg} / \mathrm{kg})$ and the placebo group $(0.4 \mathrm{mg} / \mathrm{kg})$.

Prevalence of Ascaris and Trichuris infection dropped significantly in two groups receiving MEB (Table 2). Ascaris infection slightly increased in the placebo group, however, the prevalence of Trichuris infection also decreased in the group receiving iron-fortified noodles without de-worming. Prevalence of hookworm infection decreased in all four groups; however, the prevalence of hookworm infection was very low at the baseline. The proportion of children with elevated CRP levels decreased in all three groups except the placebo group, where the number of children with elevated CRP level even increased. Prevalence of elevated $\mathrm{IgE}$ significantly decreased in all four groups, with no

Table 2. Parasite infection, inflammation and nutritional status before and after intervention in rural Vietnamese schoolchildren

\begin{tabular}{|c|c|c|c|c|}
\hline & \multicolumn{4}{|c|}{ Treatment groups§ } \\
\hline & $\begin{array}{c}\mathrm{Fe} \\
(n 86)\end{array}$ & $\begin{array}{c}\mathrm{Fe}+\mathrm{MEB} \\
(n 79)\end{array}$ & $\begin{array}{l}\text { MEB } \\
(n 79)\end{array}$ & $\begin{array}{c}\text { Placebo } \\
(n 82)\end{array}$ \\
\hline \multicolumn{5}{|l|}{ Ascaris (\%) } \\
\hline Baseline & $69 \cdot 8$ & 65.8 & $67 \cdot 1$ & $69 \cdot 5$ \\
\hline At the end ${ }^{\star \star *}$ & $68 \cdot 6$ & 44.3†† & $41.8 \dagger † \dagger$ & 74.4 \\
\hline \multicolumn{5}{|l|}{ Trichuris (\%) } \\
\hline Baseline & $76 \cdot 7$ & $78 \cdot 5$ & $63 \cdot 3$ & $73 \cdot 2$ \\
\hline At the end ${ }^{\star \star \star}$ & 47.7††† & 15.2††† & $48 \cdot 1 \dagger$ & $72 \cdot 0$ \\
\hline \multicolumn{5}{|l|}{ Hookworm (\%) } \\
\hline Baseline & $7 \cdot 0$ & $10 \cdot 1$ & $7 \cdot 6$ & $11 \cdot 0$ \\
\hline At the end ${ }^{\star \star \star}$ & $4 \cdot 7$ & $1 \cdot 3+$ & $2 \cdot 5$ & $3 \cdot 7$ \\
\hline \multicolumn{5}{|c|}{ CRP elevated $\geq 8 \mathrm{mg} / \mathrm{l}(\%)$} \\
\hline Baseline & $1 \cdot 2$ & $2 \cdot 5$ & $3 \cdot 8$ & $0 \cdot 0$ \\
\hline At the end & 0 & $1 \cdot 3$ & 0 & 3.7 \\
\hline \multicolumn{5}{|c|}{ IgE elevated > $90 \mathrm{IU} / \mathrm{ml}(\%)$} \\
\hline Baseline & $97 \cdot 7$ & $98 \cdot 7$ & 100 & $98 \cdot 8$ \\
\hline At the end & 76.5††† & 73.4††† & 78.5††† & 72.0††† \\
\hline \multicolumn{5}{|l|}{ Underweight (\%) } \\
\hline Baseline & 41.9 & 51.9 & $50 \cdot 6$ & $45 \cdot 1$ \\
\hline At the end & 33.7††† & 46.8††† & 38††† & 35.4††† \\
\hline \multicolumn{5}{|l|}{ Stunting (\%) } \\
\hline Baseline & $30 \cdot 2$ & $31 \cdot 6$ & $41 \cdot 8$ & $31 \cdot 7$ \\
\hline At the end & $29 \cdot 1$ & $27 \cdot 8$ & 29.1†† & $29 \cdot 3$ \\
\hline \multicolumn{5}{|l|}{ Wasting (\%) } \\
\hline Baseline & $9 \cdot 3$ & $16 \cdot 5$ & $13 \cdot 9$ & $12 \cdot 2$ \\
\hline At the end & 5.8†† & $17 \cdot 7$ & $13 \cdot 9$ & $13 \cdot 4$ \\
\hline
\end{tabular}

CRP, C-reactive protein

Values were significantly different between groups (one-way ANOVA): ${ }^{\star \star \star} P<0.001$. Values were significantly different within group before and after intervention (McNemar): $\dagger P<0.05 ; \dagger \dagger P<0.01 ; \dagger \dagger \dagger P<0.001$.

$\S \mathrm{Fe}$, iron-fortified noodles and placebo; $\mathrm{Fe}+\mathrm{MEB}$, iron-fortified noodles and mebendazole; MEB, noodles without iron fortificant and mebendazole; Placebo, noodles without iron fortificant and placebo; Fe tablet + MEB, iron supplementation and mebendazole. 
Table 3. Change in $\mathrm{Hb}$, anaemia and iron status during intervention in rural Vietnamese schoolchildren

\begin{tabular}{|c|c|c|c|c|c|c|c|c|}
\hline & \multicolumn{8}{|c|}{ Treatment groups§ } \\
\hline & \multicolumn{2}{|c|}{$\mathrm{Fe}(n 86)$} & \multicolumn{2}{|c|}{$\mathrm{Fe}+\mathrm{MEB}(n 79)$} & \multicolumn{2}{|c|}{ MEB $(n 79)$} & \multicolumn{2}{|c|}{ Placebo ( $n$ 82) } \\
\hline & Mean & SE & Mean & SE & Mean & SE & Mean & SE \\
\hline Change in $\mathrm{Hb}$ concentration $(\mathrm{g} / \mathrm{l})^{*}$ & $17 \cdot 83$ & $0.97 \ddagger \ddagger \ddagger$ & $17 \cdot 54$ & $0.85 \ddagger \ddagger \ddagger$ & $14 \cdot 60$ & $1.00 \ddagger \ddagger \ddagger$ & $15 \cdot 40$ & $0.92 \neq \neq \ddagger$ \\
\hline Change in serum ferritin $(\mu \mathrm{g} / \mathrm{l})^{\star \star \star}$ & $15 \cdot 05$ & $3 \cdot 28 \ddagger \ddagger \ddagger$ & $17 \cdot 86$ & $3 \cdot 61 \ddagger \ddagger \ddagger$ & -7.94 & $3.05 \ddagger \ddagger$ & $5 \cdot 37$ & $4 \cdot 31$ \\
\hline Change in TfR $(\mathrm{mg} / \mathrm{l})$ & -0.35 & $0.10 \ddagger \ddagger \ddagger$ & -0.38 & $0 \cdot 10 \ddagger \ddagger \ddagger$ & -0.39 & $0 \cdot 10$ 㧊 & -0.31 & $0 \cdot 13 \ddagger$ \\
\hline Change in body iron $(\mathrm{mg} / \mathrm{kg})^{\star \star}$ & 1.00 & $0 \cdot 20 \ddagger \ddagger \ddagger$ & $1 \cdot 39$ & $0.22 \ddagger \ddagger \ddagger$ & -0.09 & 0.18 & 0.39 & 0.20 \\
\hline \multicolumn{9}{|l|}{ Anaemia (\%) } \\
\hline Baseline & 89.5††† & & 84.8††† & & 83.5††† & & $91.5 \dagger † \dagger$ & \\
\hline At the end & $10 \cdot 5$ & & $11 \cdot 4$ & & $15 \cdot 2$ & & $19 \cdot 5$ & \\
\hline \multicolumn{9}{|l|}{ Serum ferritin $<12 \mu \mathrm{g} / \mathrm{l}(\%)$} \\
\hline Baseline & $1 \cdot 2$ & & $1 \cdot 3$ & & $1 \cdot 3$ & & $1 \cdot 2$ & \\
\hline At the end & 0 & & 0 & & 0 & & 0 & \\
\hline \multicolumn{9}{|l|}{$\mathrm{TfR}>8.5 \mathrm{mg} / \mathrm{l}(\%)$} \\
\hline Baseline & 3.5 & & $3 \cdot 8$ & & $6 \cdot 3$ & & 8.5 & \\
\hline At the end & 3.5 & & $3 \cdot 8$ & & $1 \cdot 3$ & & $6 \cdot 1$ & \\
\hline
\end{tabular}

TfR, serum transferrin receptor.

Values were significantly different between groups (one-way ANOVA): ${ }^{\star} P=0.037 ;{ }^{\star \star} P<0.01 ;{ }^{\star \star \star} P<0.001$.

Values were significantly different within group before and after intervention (McNemar): $\uparrow \dagger \uparrow P<0.001$.

Values were significantly different within group before and after intervention $(t$ test): $\ddagger P=0.02 ; \ddagger \ddagger P=0.01 ; \ddagger \ddagger \ddagger P<0.001$.

$\S \mathrm{Fe}$, iron-fortified noodles and placebo; Fe + MEB, iron-fortified noodles and mebendazole; MEB, noodles without iron fortificant and mebendazole; Placebo, noodles without iron fortificant and placebo; Fe tablet + MEB, iron supplementation and mebendazole.

differences between groups. In the ANOVA, iron-fortified noodles showed a larger change in $\mathrm{Hb}$ level $(2.6 \mathrm{~g} / \mathrm{l}$, $P=0.003)$ than the non-fortified group after taking into account $\mathrm{Hb}$ at baseline, thalassaemia, age and sex (Table 4). Increase of $\mathrm{Hb}$ level was greater in younger children compared to older children $(\beta-1 \cdot 22 ; 95 \% \mathrm{CI}-2 \cdot 2,-0 \cdot 2)$ and sex showed no effect on the improvement of $\mathrm{Hb}$ level $(\beta$ $-0.49 ; 95 \%$ CI $-2.27,1.28)$. There was no interaction effect of iron fortification and de-worming on the improvement of $\mathrm{Hb}$ level $(P=0 \cdot 93)$. Children with haemoglobinopathies showed a reduced improvement of $\mathrm{Hb}$ of $4.2 \mathrm{~g} / \mathrm{l}$.

In the two-way ANOVA, iron fortification showed a significant increase of SF $(16.3 \mu \mathrm{g} / \mathrm{l})$ while de-worming slightly decreased SF levels $(-4.6 \mu \mathrm{g} / \mathrm{l})$ after excluding children with $\mathrm{CRP} \geq 8 \mathrm{mg} / \mathrm{l}$ and adjusting for serum $\mathrm{SF}$ at baseline, age and sex (Table 4). Body iron increased $1 \mathrm{mg} / \mathrm{kg}$ after 6 months of intervention in children receiving iron-fortified noodles (Table 4). Both iron fortification and de-worming showed no effect on TfR.

After adjustment for baseline $\mathrm{Hb}$ concentration, thalassaemia, age and sex in the logistic regression analysis, the prevalence of anaemia at the end was considerably smaller after iron fortification (OR $0.37 ; 95 \%$ CI $0.17,0.80 ; P=0.01$ ), while de-worming showed no effect (OR 0.98; $95 \%$ CI $0.46,2.05 ; P=0.96)$.

\section{Discussion}

Results of the present study did not support the hypothesis that de-worming is more effective than iron fortification in an anaemic, infection-prone population that was not considered iron deficient. Remarkably, $\mathrm{Hb}$ concentrations increased and anaemia reduced in all groups, including the placebo group, during the 6 months intervention period.

Data from the present study reconfirmed the previous finding of existence of anaemia with low iron deficiency in infectionprone schoolchildren in rural Vietnam as indicated by SF and TfR. However, a positive response of $\mathrm{Hb}$ levels to iron treatment in anaemic subjects is considered to be a clear indicator of preexisting iron deficiency (Malope et al. 2001). Also in the present study population, children receiving iron-fortified noodles showed a significant improvement in $\mathrm{Hb}$, which indicates iron deficiency. SF is an acute-phase protein that may be elevated

Table 4. Differential change in $\mathrm{Hb}$, serum ferritin (SF), serum transferrin receptor (TfR) and body iron during the intervention period by treatment, compared to no treatment, from four different models $(n 320) \S$

\begin{tabular}{|c|c|c|c|c|c|c|}
\hline \multirow[b]{3}{*}{ Outcome variables } & \multicolumn{6}{|c|}{ Treatment } \\
\hline & \multicolumn{3}{|c|}{ Iron fortification } & \multicolumn{3}{|c|}{ De-worming } \\
\hline & Estimated effects & $95 \% \mathrm{Cl}$ & $P$ & Estimated effects & $95 \% \mathrm{Cl}$ & $P$ \\
\hline Change in $\mathrm{Hb}(\mathrm{g} / \mathrm{l}) \|$ & $2 \cdot 68$ & $0.89,4.47$ & 0.003 & -0.71 & $-2.50,1.08$ & 0.43 \\
\hline Change in $S F(\mu \mathrm{g} / \mathrm{l}) \boldsymbol{q}$ & $16 \cdot 32$ & $9 \cdot 46,23 \cdot 18$ & 0.001 & $-4 \cdot 60$ & $-11 \cdot 45,2 \cdot 26$ & 0.18 \\
\hline Change in TfR (mg/l)§§ & -0.03 & $-0.23,0.17$ & 0.77 & -0.03 & $-0.22,0.17$ & 0.77 \\
\hline Change in body iron $(\mathrm{mg} / \mathrm{kg}) \|$ & 1.02 & $0.66,1.37$ & 0.001 & -0.07 & $-0.43,0.28$ & 0.68 \\
\hline
\end{tabular}

§ Six children with $\mathrm{CRP} \geq 8 \mathrm{mg} / \mathrm{l}$ were excluded.

$\|$ Adjusted for $\mathrm{Hb}$ baseline, thalassaemia, sex and age.

१ Adjusted for SF baseline, C-reactive protein (CRP), sex and age.

$\S \S$ Adjusted for TfR baseline, sex and age.

\| Adjusted for body iron baseline, CRP, sex and age. 
due to infection or inflammation masking iron deficiency during infection. Malope et al. (2001) supposed that SF values between 12 and $100 \mu \mathrm{g} / \mathrm{l}$ can still indicate iron deficiency especially in the presence of infection and inflammation. However, considering the low prevalence of elevated CRP in the present study population, it seems unlikely that acute infection is affecting the SF levels. TfR has an advantage over SF as it is unaffected by the acute-phase response (Ritchie et al. 2004) and is therefore considered to be a sensitive indicator of iron status in children (Asobayire et al. 2001). However, the diagnostic cut-offs for TfR used to identify iron deficiency were derived from studies in adults (Anonymous, 2000). These cut-offs may not apply to children due to their increased erythropoeisis during growth (Kling et al. 1998). Based on a study conducted in Morocco and Côte d'Ivoire, Zimmerman et al. (2005) suggest a lower cut-off point for white compared to black Africans although the differences between suggested cut-off points are small. In addition, researchers indicate, regardless of diagnostic cut-offs, modest sensitivity and specificity of TfR in identifying iron deficiency in children (Ritchie et al. 2004; Zimmermann et al. 2005).

Based on the previous study indicating that Trichuris infection was associated with a doubled risk of anaemia, we expected an improved $\mathrm{Hb}$ level after de-worming. The results of the present study, however, did not support this hypothesis as de-worming showed no effect on $\mathrm{Hb}$ levels and iron status. The Trichuris infection in the present study population was classified as mild. Therefore, the absence of effect is in line with the previous studies showing that blood loss can occur in Trichuris infection, but probably becomes significant only in severe infection (Layrisse et al. 1967; Stephenson, 1987; Stephenson et al. 2000). MEB treatment was given directly to children at school by researchers and field staff, and the two groups receiving MEB showed a larger reduction in prevalence of all three types of worms. Surprisingly, the effects on Trichuris in both groups receiving iron were remarkable and indicate interplay between certain helminth infections and iron. More data are becoming available suggesting that iron (and other micronutrients) has important effects on the natural resistance to parasites and that iron supplementation may reduce parasite infection. Studying Trichuris suis, Pedersen et al. (2001) found that iron deficiency increased the severity of $T$. suis in pigs. It has recently been documented that adults given supplemental iron have significantly lower reinfection rates of Trichuris trichiura, Ascaris lumbricoides and Schistosoma mansoni infection (Olsen et al. 2000). The effect was suggested to be due to reduced risk behaviour, to improved immune function or to unfavourable host gut conditions caused by an increased oxidative stress.

Remarkably, $\mathrm{Hb}$ increased and anaemia reduced in all groups, including the placebo group, during the intervention period. Hb levels are mainly a function of red blood cell production and turnover, affected by factors other than iron deficiency in the present study population. A study in schoolchildren in north-east Thailand found a high prevalence of anaemia without iron deficiency, with haemoglobinopathies, suboptimal vitamin A status and age as the major predictors of $\mathrm{Hb}$ concentration (Thurlow et al. 2005). Another study in school-age children in Alaska, with $15 \%$ anaemia and $8 \%$ being iron deficient, showed an association between a bacterial infection (Helicobacter pylori) and anaemia (Baggett et al.
2006). Data from the present study indicated that the prevalence of thalassaemia was very low and therefore could not explain the high prevalence of anaemia in the study population. Vitamin A status is considered to be a major determinant of anaemia (Gamble et al. 2004), but sub-samples ( $n$ 81) analysed for serum retinol levels showed a very low prevalence of suboptimal vitamin A deficiency (8 and $6 \%$ with serum retinol concentration $<0.70 \mu \mathrm{mol} / \mathrm{l}$ at baseline and after intervention, respectively). Other nutrient deficiencies associated with anaemia include deficiencies of vitamins B6, B12, riboflavin and folic acid (Broek \& Letsky, 2000), although not all of the causal pathways are yet clearly understood. Vitamin B12 and folic acid deficiency are associated with an increased TfR (Gibson, 2005), but we did not observe elevated TfR levels in the present study population. The role of other nutrients could not be verified in the present study. Malaria remains another important cause of anaemia in tropical countries (Phillips \& Pasvol, 1992; Cardoso et al. 1994), however, malaria was not present in the study area.

The increase of Hb levels in all groups, including the placebo group, might be due to an increase in iron intake due to a seasonal change in food habits or an increase in energy intake through the noodles. We do not have reason to believe there is a seasonal increase in iron intake. A food consumption study among a sub-sample of fifty-nine children (data not shown) showed no change in iron intake between October (baseline) and January, but we did not measure iron intake at the end of intervention (May). Although the noodles intervention did increase energy intake in the sub-sample, we do not think this caused the improvement of $\mathrm{Hb}$ levels, as the iron supplementation with de-worming group (the 'standard' treatment who did not receive noodles) also showed a $\mathrm{Hb}$ improvement (data not shown).

In the absence of the aforementioned causes of anaemia and the observed improvements in the placebo group, the present data may suggest the presence of anaemia of inflammation. Firstly, SF in the study population was much higher compared to the 50th percentile SF value $(28.7 \mu \mathrm{g} / \mathrm{l})$ for the age group 6-9 years in NHANES III (Gibson, 2005), being close to the 90 th percentile level of $55.9 \mu \mathrm{g} / \mathrm{l}$. This may indicate that inflammation is of a more chronic nature. Secondly, Malope et al. (2001) suggest the use of log TfR:SF ratio to differentiate between iron deficiency anaemia (ratio $>2.55$ ) and anaemia of inflammation (ratio $<2.55$ ), although the latter ratio was not able to exclude iron deficiency. In the present study the ratio of $\log$ TfR:SF was $2 \cdot 06$, indicating the existence of anaemia of inflammation but being unable to exclude iron deficiency. Children from the placebo group not receiving iron showed increased $\mathrm{Hb}$ levels, having a log TfR:SF ratio of 2.07, accompanied by absence of increase (in placebo) or even decrease (in de-worming only) in SF. This indicates a shift of iron from storage to $\mathrm{Hb}$ and according to Malope et al. (2001) this suggests that besides iron deficiency another likely cause of anaemia in the children was infection which improved during the supplementation trial. Thirdly, the seasonal burden of infections in developing countries has been recognized for many years by agricultural and health professionals (Tomkins, 2005). Mild inflammatory conditions such as upper-respiratory infections and otitis media, which remain common in early childhood, may contribute to anaemia (Yip \& Dallman, 1988). In the study population the 
proportion of children with elevated CRP is very low. However, CRP is a good measure of acute infection or inflammation but less appropriate when conditions are chronic (Looker et al. 1997). Earlier a relationship between $\operatorname{IgE}$ and respiratory disease was found (Hodge et al. 2001). In our previous study, Trichuris infection was associated with IgE levels which could have confounded the association of Trichuris with anaemia and $\mathrm{Hb}$ concentration. De-worming apparently did not affect $\operatorname{IgE}$ levels and if the assumption holds true that another unknown infection reflected by IgE plays a role in the anaemia in the study population, this would explain the absence of de-worming effect. In the present study, the high level of $\mathrm{IgE}$ and the reduction of $\mathrm{IgE}$ levels concurrently with reduction of anaemia independent of treatment may suggest that chronic infection may and intestinal parasite infection may not play a role in inflammation anaemia. Finally, the present data indicated that at the baseline $38.7 \%$ children reported fever or respiratory infection in the previous 2 weeks but at the end survey this prevalence reduced to $13.2 \%$ (data not shown). We did not find an association between fever and respiratory infection with anaemia, however, the reduction in fever and respiratory infection may reflect a general reduction of infection status during the intervention period in the study population. This supports our speculation that anaemia is associated with chronic infection in the present study population and that the anaemia reduction observed in the placebo group may be due to a seasonal reduction of chronic infection. However, the role of chronic infections in anaemia needs to be further investigated.

In conclusion, iron fortification slightly improved anaemia and iron status in anaemic schoolchildren in rural Vietnam that were not considered iron deficient. De-worming reduced prevalence of worm infection but had no effect on anaemia and iron status. A positive seasonal effect was seen in all treatment groups. Chronic infection or other unidentified factors including a limited iron uptake for haem synthesis may play an important role.

\section{Acknowledgements}

This study was funded by Neys-van Hoogstraten Foundation, Ellison Medical Foundation and the Ministry of Education and Training, Vietnam. Akzo Nobel Chemicals, Arnhem, The Netherlands, is acknowledged for supplying NaFeEDTA. Hospital De Gelderse Vallei, Ede, The Netherlands is thanked for preparation of MEB and identical placebo. The authors acknowledge the assistance of the Directors, teachers and children from the six schools, the Director and staff of the Education Department, and the Director and staff of the District Health Center in Tam Nong district Phu Tho province. Prof. Dr Renger Witkamp is acknowledged for his valuable remarks on earlier versions of the paper.

\section{References}

Anonymous (2000) Iron Deficiency Anaemia: Assessment, Prevention and Control. Geneva: World Health Organization.

Asobayire FS, Adou P, Davidsson L, Cook JD \& Hurrell RF (2001) Prevalence of iron deficiency with and without concurrent anaemia in population groups with high prevalences of malaria and other infections: a study in Côte d'Ivoire. Am J Clin Nutr 74, $776-782$

Baggett HC, Parkinson AJ, Muth PT, Gold BD \& Gessner BD (2006) Endemic iron deficiency associated with Helicobacter pylori infection among school-aged children in Alaska. Pediatrics 117, e396-e404.

Broek N van den \& Letsky E (2000) Etiology of anemia in pregnancy in south Malawi. Am J Clin Nutr 72, 247S-256S.

Cardoso M, Ferreira M, Camargo L \& Szarfarc S (1994) Anaemia, iron deficiency and malaria in a rural community in Brazilian Amazon. Eur J Clin Nutr 48, 326-332.

Cook JD, Flowers CH \& Skikne BS (2003) The quantitative assessment of body iron. Blood 101, 3359-3364.

Dean AG, Dean JA, Coulombier D, et al. (1995) Epi Info Version 6: A Word-processing, Database and Statistics Program for Public Health on IBM-compatible Microcomputer. Atlanta, GA: Center for Disease Control and Prevention.

Dugdale M (2001) Anemia. Obstet Gynecol Clin North Am 28, $363-381$.

Field A (2005) Discovering Statistics Using SPSS for Windows, 2nd ed., London: Sage Publications.

Fleming A (1981) Haematologic manifestations of malaria and other parasitic diseases. Clin Haematol 10, 983-1011.

Food and Agriculture Organization \& World Health Organization (1998) Requirement of Vitamin A, Iron, Folate and Vitamin B12. FAO Food and Nutrition Series no. 32. Rome: FAO.

Gamble M, Palafox N, Dancheck B, Ricks M, Briand K \& Semba R (2004) Relationship of vitamin A deficiency, iron deficiency, and inflammation to anemia among preschool children in the Republic of the Marshall Islands. Eur J Clin Nutr 58, 1396-1401.

Gibson RS (2005) Principles of Nutrition Assessment, 2nd ed., Oxford: Oxford University Press.

Heil W, Koberstein R \& Zawta B (2000) Reference Ranges for Adults and Children: Pre-Analytical Considerations no. 133. Mannheim: Roche Diagnostics.

Hoa DT (2002) Effect of fortified biscuit with vitamin A and iron on vitamin A status and anemia in primary school children in suburban Vietnam. PhD Thesis, : Hanoi Medical University.

Hodge LM, Mrinaro M, Jones HP, McGhee JR, Kiyono H \& Simecka JW (2001) Immunoglobulin A (IgA) responses and IgE-associated inflammation along the respiratory tract after mucosal but not systemic immunization. Infect Immun 69, 2328-2338.

Hoffbrand A \& Pettit J (1993) Essential Haematology. Oxford: Blackwell Scientific Publications.

Hurrell R (1997) Preventing iron deficiency through food fortification. Nutr Rev 55, 210-222.

INACG (2002) Anemia, Iron Deficiency and Iron Deficiency Anemia. Washington, DC: ILSI Research Foundation.

JECFA (1974) Toxicological Evaluation of Some Food Additives Including Anticaking agents, Antimicrobials, Antioxidants, Emulsifiers and Thickening Agents. Joint FAO/WHO Expert Committee on Food Additives. WHO Technical Report Series no. 539. Geneva: World Health Organization.

Kling P, Roberts R \& Widness J (1998) Plasma transferrin receptor levels and indices of erythropoiesis and iron status in healthy term infants. J Pediatr Hematol Oncol 20, 309-314.

Layrisse M, Aparcedo L, Martinez C \& Roche M (1967) Blood loss due to infection with Trichuris trichiura. Am J Trop Med Hyg 16, 613-619.

Le HT (1999) Nutritional status and related factors of primary school children in Hanoi and sub urban Hanoi. Masters Thesis, Hanoi Medical University.

Le HT (2006) Anemia among schoolchildren in Vietnam: the efficacy of iron fortification. $\mathrm{PhD}$ Thesis, Wageningen University.

Le HT, Brouwer ID, Verhoef H, Khan NC \& Kok FJ (2005) Determinants of anaemia in infection-prone school children in rural Vietnam. S Afr J Clin Nutr 49, 140. 
Looker A, Dallman P, Carroll M, Gunter E \& Johnson C (1997) Prevalence of iron deficiency in the United States. JAMA 277, 973-976.

Malope BI, MacPhail AP, Alberts M \& Hiss DC (2001) The ratio of serum transferrin receptor and serum ferritin in the diagnosis of iron status. $\mathrm{Br}$ J Haematol 115, 84-89.

Means RJ (2000) The anaemia of infection. Baillieres Best Pract Res Clin Haematol 13, 151-162.

Ninh NX, Khan NC \& Khoi HH (2001) Micronutrient deficiencies and strategies for their control in Vietnam. In 20 Years of Prevention and Control of Micronutrient Deficiency in Vietnam, pp. 24-33 [NX Ninh, NC Khan, HH Khoi and NT Lam, editors]. Hanoi: Medical Publishing House.

Olsen A, Nawiri J \& Friis H (2000) The impact of iron supplementation on reinfection with intestinal helminths and Schistosoma mansoni in western Kenya. Trans $R$ Soc Trop Med Hyg 94, 493-499.

Osório MM (2002) Determinant factors of anemia in children. J Pediatr 78, 269-278.

Pedersen S, Saeed I, Friis H \& Michaelsen KF (2001) Effect of iron deficiency on Trichuris suis and Ascaris suum infections in pigs. Parasitology 122, 589-598.

Phillips R \& Pasvol G (1992) Anaemia of Plasmodium falciparum malaria. Baillieres Best Pract Res Clin Haematol 5, 315-330.

Ritchie B, McNeil Y \& Brewster D (2004) Soluble transferrin receptor in Aboriginal children with a high prevalence of iron deficiency and infection. Trop Med Int Health 9, 96-105.

Sheppard L \& Henion J (1997) Quantitative capillary electrophoresis/ ion spray tandem mass spectrometry determination of EDTA in human plasma and urine. Analyt Chem 69, 2901-2907.

Skikne B, Flowers C \& Cook JD (1990) Serum transferrin receptor: a quantitative measure of tissue iron deficiency. Blood 75, 1870-1876.

Stephenson LS (1987) The Impact of Helminth Infection on Human Nutrition. London: Taylor \& Francis.
Stephenson LS, Holland CV \& Cooper ES (2000) The public health significance of Trichuris trichiura. Parasitology 121, S73-S95.

Stoltzfus R, Chwaya H, Montresor A, Albonico M, Savioli L \& Tielsch J (2000) Malaria, hookworms and recent fever related to anemia and iron status indicators in 0- to 5-y Zanzibari children and these relationships change with age. J Nutr 130, $1724-1733$.

Stoltzfus R, Chwaya H, Tielsch J, Schulze K, Albonco M \& Savioli L (1997) Epidemiology of iron deficiency anemia in Zanzibari school children: the importance of hookworms. Am J Clin Nutr 65, $153-159$.

Thurlow RA, Winichagoon P, Green $T$, Wasantwisut E, Pongcharoen T, Bailey KB \& Gibson RS (2005) Only a small proportion of anemia in northeast Thai schoolchildren is associated with iron deficiency. Am J Clin Nutr 82, 380-387.

Tomkins A (2005) Environment, Season and Infection. Cambridge: Cambridge University Press.

World Health Organization (1987) Prevention and Control Intestinal Parasitic Infections. Report of a WHO Expert Committee. Technical Report Series no. 749. Geneva: WHO.

World Health Organization (1991) Basic Laboratory Methods in Medical Parasitology. Geneva: WHO.

World Health Organization (1995) Physical Status, the Use and Interpretation of Anthropometry. WHO Technical Report Series no. 854. Geneva: WHO.

World Health Organization (2000) Iron Deficiency Anaemia: Assessment, Prevention and Control. Geneva: WHO.

Yip R \& Dallman PR (1988) The roles of inflammation and iron deficiency as causes of anemia. Am J Clin Nutr 48, 1295-1300.

Zimmermann MB, Molinari L, Staubli-Asobayire F, Hess SY, Chaouki N, Adou P \& Hurrell RF (2005) Serum transferrin receptor and zinc protoporphyrin as indicators of iron status in African children. Am J Clin Nutr 81, 615-623. 